\title{
STABILITY OF TRANSVERSE VIBRATION OF DRILLSTRING CONVEYING DRILLING FLUID
}

\author{
Song Tang, Zheng Liang, Guang-Hui Zhao \\ School of Mechanical Engineering, Southwest Petroleum University, Chengdu, China \\ e-mail: st_4455@126.com; liangz_2242@126.com; wy_zgh@126.com
}

\begin{abstract}
In this paper, an analytical model is proposed to predict lateral vibration of a drillstring in a vertical well. The effect of parameters, such as stiffness of spring, average weight on bit (WOB), amplitude of fluctuating WOB and so on, on the dynamic stability of the drillstring is discussed. It is found that the interaction between the drillstring and drilling mud has a great influence on drillstring buckling and dynamics. For constant drilling pressure, the mud flow rate stabilizes the drillstring under certain conditions, but the fluctuating WOB drives the drillstring parametric resonance.
\end{abstract}

Keywords: drillstring, fluid-pipe coupling, fluctuating WOB, stability, Galerkin method

\section{Introduction}

In the course of drilling operation, the movement of the drillstring is limited to a narrow wellbore, and the forces exerted on the drillstring are extremely complex. Under its own gravity, together with the interaction of the weight on bit (WOB) and drilling mud, the drillstring may lose stability. It is characteristic that the amplitude of drillstring lateral deflection increases monotonically and intense collision between the drillstring and borehole wall will occur. It is an important cause of premature failure of the drillstring and deterioration of the well trajectory (Ghasemloonia et al., 2013).

The drillstring can be seen as a pipe conveying fluid that flows inside and outside the pipe, which is constrained by a wellbore. The dynamics of fluid-conveying pipes has been of considerable interest in the world (Wang et al., 2010; Païdoussis et al., 2008). Since the diameter is much smaller than its length, the pipe is usually simplified to be an Euler-Bernoulli beam. Based on stability analysis of pipes with steady flow (Païdoussis and Issid, 1974), the impact of the flow rate pulsation on stability has attracted widespread attention. Panda and Kar (2008) took the amplitude and frequency detuning of harmonic velocity perturbation as control parameters, and investigated bifurcation of pipes with simply supported ends as well as the effect of internal resonances on dynamic responses using the method of multiple scales. Łuczko and Czerwiński (2015) applied the Galerkin method and the Floquet theory to parametric vibrations of flexible hoses excited by a pulsating fluid flow, in which both parametric resonance ranges and regions of an increased vibration level were discussed. Nonlinear dynamics of simply supported pipes that conveyed pulsating fluid and were constrained by cubic springs was investigated by Wang (2009), who paid more attention to the system with a higher mean velocity. The cumulative effect of geometric and constrained nonlinearity was also discussed. Wang (2012) investigated buckling and flutter instabilities of supported fluid-conveying pipes subjected to distributed follower forces through the Galerkin method. Ni et al. (2015) worked on nonlinear dynamics of a cantilevered pipe conveying fluid interacting with two support walls on both sides via the Galerkin method and the fourth-order Runge-Kutta method, where the interaction force was modeled by a trilinear spring. In general, dynamic models of fluid-conveying pipes include only 
the coupling effect between the pipe and internal fluid, and length of the pipe is far less than that of the oil drilling pipe. Therefore, dynamics of the pipe conveying fluid is different from that of a very slender drillstring system with internal and external drilling fluids as well as drilling loads.

For a pipe string constrained simultaneously by internal and external fluid, Païdoussis et al. (2008) generalized the study of the tubular cantilever conveying fluid to an idealized flow-powered drillstring-like system with a floating drill-bit. The outer diameter and length of the drillstring were $0.5 \mathrm{~m}$ and $1000 \mathrm{~m}$, respectively, and the influence of the internal and annular flow of the drilling fluid on system stability was discussed. Qian et al. (2008) studied dynamics of a drillstring-like system under a counterflush drilling process in which the drilling fluid was pumped down in an annular region and flowed axially upwards inside the pipe. Tang et al. (2018) studied dynamic stability of lateral vibration of a tubing string in flowing production. Abdelbaki et al. $(2019,2020)$ investigated nonlinear transverse vibration for a hanging cantilevered pipe with fully-confined external flow and a partially-confined external flow. Comparing with the real drilling system, the drillstring-like system did not include the downhole WOB, and the lateral size was much larger. It results in a big difference in stiffness characteristics between these two systems, and the axial load at the bottom is ignored.

The drillstring vibration is divided into three vibration forms, such as lateral, axial and torsional vibration, and the drillstring can undergo a coupled state of vibration. But the lateral vibration is typically the most severe form in the conventional drilling (Ghasemloonia et al., 2014). The decoupled model can reveal well rich dynamical behavior and stability of a cylinder that is similar to the drillstring with supported ends subjected to both internal and external axials flows. The theoretical and experimental results were in good agreement (Hannoyer and Païdoussis, 1978).

In the research of transverse vibration and stability of a drillstring, Euler-Bernoulli beam theory is adopted for the most part. Dunayevsky et al. (1993) established a parametric resonance model of a drillstring, and studied rapidly growing lateral vibrations triggered by WOB fluctuations. Ren and Yao (2013) investigated dynamics of a compressed drillstring that was in a horizontal well and simplified it to be a revolving pinned-pinned uniform beam. A period doubling bifurcation of the system was presented through the Galerkin method and the multi-scales method. Ghasemloonia et al. (2014) simulated coupled axial-transverse vibration of a drillstring in vibration-assisted rotary drilling by the Galerkin method. Umbetkulova and Khajiyeva (2017) studied nonlinear transverse vibrations caused by the action of a variable compressive load and initial curvature of the drill string. Wen et al. (2019) designed a set of experimental devices to simulate transverse vibrations of a rotary drill string in a highly deviated well. The drillstring transverse vibration laws were studied quantitatively under different rotary speeds and weight on bit (WOB). Mohammadzadeh et al. (2020) proposed fully coupled nonlinear vibration of composite drillstrings, which consisted of orthotropic layers. Fully coupled nonlinear vibrations and modal analysis of the composite drillstrings due to various fiber orientations and stacking sequences in different drilling conditions were studied. Due to complexity of the drillstring dynamics, hydrodynamic forces from the drilling mud were not involved in the models above.

Drilling mud flows downwards through the drill pipe internally to the bottom and goes up with the cuttings produced while drilling to the surface in the annulus. Fluid-pipe interaction has a great influence on transverse vibration and stability of the drillstring, nevertheless, papers in this aspect are not too much. Zhang and Miska (2005) studied the effect of flow-pipe interaction on drill pipe buckling and dynamics. Asghar Jafari et al. (2012) described drilling mud forces by formulations delivered by Païdoussis et al. (2008), and established the integral energy equations by means of the Lagrangian approach to analyze lateral vibration and stability of the drillstring system. In this model, the effect of drilling parameters on the neutral point and natural frequen- 
cies was discussed by the finite element method. Pei et al. (2013) modeled lateral vibration of a vertical rotating drillstring conveying mud by rotor dynamics, in which the rotational inertia and the gyroscopic effect were involved, and the effect of various parameters on stability of the drillstring system was analyzed using the Galerkin method and eigenvalue analysis. All of these models were focused on the constant WOB, and the drilling pressure fluctuation was ignored.

In this paper, an analytical model, which includes the interaction of the fluctuating WOB and drilling mud that flows downwards inside the drillstring and upwards in the annular region, is established to predict lateral vibration of the drillstring in a vertical well. This model is discretized by Galerkin's technique, and stability of the drillstring system with constant WOB and fluctuating WOB is analyzed by generalized eigenvalue analysis and Bolotin's method, respectively. The effect of parameters, such as stiffness of spring, WOB, borehole size, flow rate and density of drilling mud on stable zones is discussed.

\section{The equation of motion}

The drillstring in the vertical well is simplified to be a uniform pipe constrained by a fixed hinge at well head and the movable hinge at the downhole. Here, the stabilizer is modeled as a linear spring (Fig. 1). The origin of coordinates is located at the wellhead, and $x$-axis coincides with both the centerline of the borehole and the initial configuration of the drillstring whose lateral displacement is expressed as $w(x, t)$. The drilling fluid, which is pumped downward to the bottom in the central channel of the drill pipe, then flows upward to the ground in the annulus formed by the drillstring and borehole wall after through a bit.

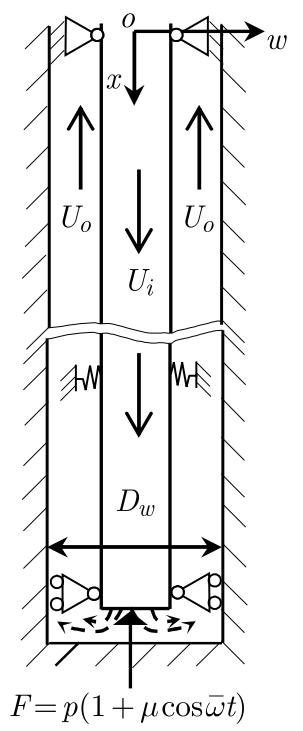

Fig. 1. Sketch of drillstring

In the drilling case of using a PDC bit or an impregnated diamond bit, drill pressure that does not fluctuate significantly with time could be set as a constant value approximately. However, the three-cone bit hits the bottom of the well with a single tooth and double-tooth alternately, and causes the drillstring vibrating longitudinally. Generally, the WOB exerted on the three-cone bit could be simplified as a harmonic excitation. Considering the fluctuating WOB, drillstring gravity, hydrodynamic force due to the internal and external flow, the equation of lateral vibration of the drillstring can be deduced by means of force balances of small elements of the tubular beam, internal fluid and external fluid (Païdoussis et al., 2008) 


$$
\begin{aligned}
E I & \frac{\partial^{4} w}{\partial x^{4}}+M_{t} \frac{\partial^{2} w}{\partial t^{2}}+M_{f}\left(\frac{\partial^{2} w}{\partial t^{2}}+2 U_{i} \frac{\partial^{2} w}{\partial t \partial x}+U_{i}^{2} \frac{\partial^{2} w}{\partial x^{2}}\right)+\chi \rho A_{o}\left(\frac{\partial^{2} w}{\partial t^{2}}-2 U_{o} \frac{\partial^{2} w}{\partial t \partial x}+U_{o}^{2} \frac{\partial^{2} w}{\partial x^{2}}\right) \\
- & {\left[\left(A_{o} p_{o l}-A_{f} p_{i l}\right)-p(1+\mu \cos \bar{\omega} t)+\left(M_{t}+M_{f}-\rho A_{o}\right) g(l-x)\right.} \\
& -\frac{1}{2} C_{f} \rho D_{o} U_{o}^{2}\left(1+\frac{D_{o}}{D_{h}}(l-x)\right] \frac{\partial^{2} w}{\partial x^{2}}+\left[\left(M_{t}+M_{f}-\rho A_{o}\right) g\right. \\
& \left.-\frac{1}{2} C_{f} \rho D_{o} U_{o}^{2}\left(1+\frac{D_{o}}{D_{h}}\right)\right] \frac{\partial w}{\partial x}+\frac{1}{2} C_{f} \rho D_{o} U_{o} \frac{\partial w}{\partial t}+k \frac{\partial w}{\partial t}+\delta\left(x-x_{s t a b}\right) k_{s t a b} w=0
\end{aligned}
$$

where $l$ is the total length of the drillstring, $E I$ is flexural rigidity, $M_{t}$ is mass per unit length of the drillstring whose inner and outer diameters are $D_{i}$ and $D_{o}$, respectively. $\rho$ is density of the drilling fluid and $M_{f}$ is mass per unit length of the fluid transported with a velocity $U_{i}$ and a cross section $A_{f}$ inside the drillstring. $\chi$ is the added mass coefficient for the annular flow and defined as: $\chi=\left[\left(D_{w} / D_{o}\right)^{2}+1\right] /\left[\left(D_{w} / D_{o}\right)^{2}-1\right]$, where $D_{w}$ is the inner diameter of the wellbore. $D_{h}$, described as $D_{h}=4 A_{c h} /\left[\pi\left(D_{w}+D_{0}\right)\right]$, is the hydraulic diameter of the annular channel flow with a velocity $U_{o}$ and a cross section $A_{c h}$. $U_{i}$ and $U_{o}$ are related through the continuity equation, $U_{o}=A f U_{i} / A_{c h} . p$ and $p \mu \cos \bar{\omega} t$ are the constant and harmonic component of WOB, respectively, where $\bar{\omega}$ is the circular frequency that could be expressed by the rotation speed $N$ as $\bar{\omega}=3(2 N \pi / 60)$ approximately for the three-cone bit. $p_{i l}$ and $p_{o l}$ are fluid pressure inside and outside the drillstring at the bottom hole, respectively. $C_{f}$ is the viscous coefficient due to the external axial flow. $k$ is the viscous damping coefficient related to the circular frequency of drillstring oscillation $\omega^{\prime}$ and shown as

$$
k=\sqrt{2 \nu \omega^{\prime}} \pi \rho D_{o} \frac{1+\left(D_{w} / D_{o}\right)^{3}}{\left[1-\left(D_{w} / D_{o}\right)^{2}\right]^{2}}
$$

where $\nu$ is the kinematic viscosity of the drilling fluid, $x_{s t a b}$ is location of the stabilizer, $k_{s t a b}$ is the stiffness parameter of the stabilizer, $\delta(x)$ is the impulsive function, $\delta(x)=1$ if $x=0$, and $\delta(x)=0$ if $x \neq 0$.

Boundary conditions of this model are given by

$$
w(0, t)=\frac{\partial^{2} w}{\partial x^{2}}(0, t)=0 \quad w(l, t)=\frac{\partial^{2} w}{\partial x^{2}}(l, t)=0
$$

For convenience, the following dimensionless quantities are introduced

$$
\begin{aligned}
& \eta=\frac{w}{l} \quad \xi=\frac{x}{l} \quad \xi_{\text {stab }}=\frac{x_{\text {stab }}}{l} \quad \tau=\frac{t}{l^{2}} \sqrt{\frac{E I}{M_{t}+M_{f}+\rho A_{o}}} \\
& \omega=l^{2} \bar{\omega} \sqrt{\frac{M_{t}+M_{f}+\rho A_{o}}{E I}} \quad u_{i}=\sqrt{\frac{M_{f}}{E I}} U_{i} l \quad u_{o}=\sqrt{\frac{\rho A_{o}}{E I}} U_{o} l \\
& \beta_{o}=\frac{\rho A_{o}}{M_{t}+M_{f}+\rho A_{o}} \quad \beta_{i}=\frac{M_{f}}{M_{t}+M_{f}+\rho A_{o}} \quad \gamma=\frac{\left(M_{t}+M_{f}-\rho A_{o}\right) g l^{3}}{E I} \\
& \Gamma=\frac{p l^{2}}{E I} \quad \Pi_{i l}=\frac{p_{i l} A_{f} l^{2}}{E I} \quad \Pi_{o l}=\frac{p_{o l} A_{o} l^{2}}{E I} \quad c_{f}=\frac{4 C_{f}}{\pi} \\
& \varepsilon=\frac{l}{D_{o}} \quad h=\frac{D_{o}}{D_{h}} \quad \kappa=\frac{k l^{2}}{E I \sqrt{M_{t}+M_{f}+\rho A_{o}}} \quad \kappa_{s t a b}=\frac{k_{s t a b} l^{3}}{E I} \\
& \alpha=\frac{D_{i}}{D_{o}} \quad \alpha_{c h}=\frac{D_{w}}{D_{o}}
\end{aligned}
$$


Substituting the expressions above into Eq. (2.1), the dimensionless form of the governing equation is

$$
\begin{gathered}
\frac{\partial^{4} \eta}{\partial \xi^{4}}+a \frac{\partial^{2} \eta}{\partial \tau^{2}}+b \frac{\partial^{2} \eta}{\partial \tau \partial \xi}+[c-d(1-\xi)+\mu \Gamma \cos \omega \tau] \frac{\partial^{2} \eta}{\partial \xi^{2}} \\
+d \frac{\partial \eta}{\partial \xi}+e \frac{\partial \eta}{\partial \tau}+\delta\left(\xi-\xi_{\text {stab }}\right) \kappa_{\text {stab }} \eta=0
\end{gathered}
$$

where

$$
\begin{array}{ccc}
a=1+\beta_{o}(\chi-1) \quad b=2\left(u_{i} \sqrt{\beta_{i}}-\chi u_{o} \sqrt{\beta_{o}}\right) & c=u_{i}^{2}+\chi u_{o}^{2}+\Pi_{i l}-\Pi_{o l}+\Gamma \\
d=\gamma-\frac{1}{2} c_{f} \varepsilon u_{o}^{2}(1+h) \quad e=\frac{1}{2} c_{f} \varepsilon u_{o} \sqrt{\beta_{o}}+\kappa &
\end{array}
$$

The dimensionless boundary conditions are

$$
\eta(0, \tau)=\frac{\partial^{2} \eta}{\partial \xi^{2}}(0, \tau)=0 \quad \eta(1, \tau)=\frac{\partial^{2} \eta}{\partial \xi^{2}}(1, \tau)=0
$$

\section{Methods of solution}

Equation (2.3) could be discretized into ordinary differential equations by many methods. Comparing with the hybrid Galerkin-Fourier method and Differential Quadrature Method, the conventional Galerkin method is used more widely for its simplicity and convenience of computation, and for the problem at hand. The dimensionless displacement function of the drillstring model could be expressed as

$$
\eta(\xi, \tau)=\mathbf{\Phi q}^{\mathrm{T}}
$$

where $\boldsymbol{\Phi}=\left[\phi_{1}(\xi), \phi_{2}(\xi), \ldots, \phi_{n}(\xi)\right]$ is the vector of mode function of a simple-supported beam and $\phi_{i}=\sin i \pi \xi, i=1,2, \ldots, n ; \mathbf{q}=\left[q_{1}(\tau), q_{2}(\tau), \ldots, q_{n}(\tau)\right]$ is the vector of generalized coordinates. Substituting Eq. (3.1) into Eq. (2.3), and integrating over $\xi$ from 0 to 1, one obtains

$$
\ddot{\mathbf{q}}+\mathbf{C} \dot{\mathbf{q}}+(\mathbf{K}+\Gamma \mu \cos \omega \tau \mathbf{B}) \mathbf{q}=\mathbf{0}
$$

in which $\mathbf{C}, \mathbf{K}$ and $\mathbf{B}$ are square matrices of the order $n ; \mathbf{C}$ and $\mathbf{K}$ represent damping and stiffness matrices, respectively. The elements of $\mathbf{C}, \mathbf{K}$ and $\mathbf{B}$ are given by

$$
\begin{aligned}
C_{i j} & =\frac{1}{a}\left(b \Lambda_{i j}+e \delta_{i j}\right) \quad B_{i j}=-\frac{1}{a}(i \pi)^{2} \delta_{i j} \\
K_{i j} & =\frac{1}{a}\left[(i \pi)^{4} \delta_{i j}-(c+d)(i \pi)^{2} \delta_{i j}+d\left(\Lambda_{i j}+D_{i j}\right)+\kappa_{s t a b} \Theta\right]
\end{aligned}
$$

where $\delta_{i j}$ is Kronecker's delta, $\Theta=\sin \left(i \pi \xi_{s t a b}\right) \sin \left(j \pi \xi_{s t a b}\right)$, and $\Lambda_{i j}$ and $D_{i j}$ could be written as

$$
\Lambda_{i j}=\left\{\begin{array}{ll}
\frac{i j}{i^{2}-j^{2}}\left[1-(-1)^{i+j}\right] & i \neq j \\
0 & i=j
\end{array} \quad D_{i j}= \begin{cases}\frac{4 i j^{3}}{\left(i^{2}-j^{2}\right)^{2}}\left[1-(-1)^{i+j}\right] & i \neq j \\
\frac{-(i \pi)^{4}}{4} & i=j\end{cases}\right.
$$

Based on the above model and methods, dynamic stability of the drillstring system will be discussed in both cases of constant WOB (corresponding to drilling operation with PDC bit or impregnated diamond bit) and harmonic WOB (corresponding to the three-cone bit), respectively. 


\section{Stability analysis under constant WOB}

The drillstring system considered is a very slender beam with $l=1000 \mathrm{~m}, D_{i}=101.6 \mathrm{~mm}$, $D_{o}=127 \mathrm{~mm}, D_{w}=241.5 \mathrm{~mm}, M_{t}=43.75 \mathrm{~kg} / \mathrm{m}, E=200 \mathrm{GPa}, \rho=1200 \mathrm{~kg} / \mathrm{m}^{3}$, $\nu=10^{-6} \mathrm{~m}^{2} / \mathrm{s}, x_{\text {stab }}=800 \mathrm{~m}$, and $k_{\text {stab }}=0 \mathrm{MN} / \mathrm{m}$. The damping coefficient of the drilling fluid is composed of the frictional damping coefficient $C_{f}$ and the viscous damping coefficient $k$. $C_{f}$ could be chosen as a semi-empirical value of 0.0125 referring to (Païdoussis et al., 2008). $k$, which is related to the natural frequency of the system, could be determined by calculating iteratively for each mode. Here, eigenvalue evolution will be presented to show stability of the system.

\subsection{Eigenvalue analysis}

When the WOB keeps constant, that is $\mu=0$, Eq.(3.2) is simplified to

$$
\ddot{\mathbf{q}}+\mathbf{C} \dot{\mathbf{q}}+\mathbf{K q}=\mathbf{0}
$$

whose solution could be written as: $\mathbf{q}=\overline{\mathbf{q}} \exp \left(\omega_{n} \tau\right)$, where $\overline{\mathbf{q}}$ is an unknown vector of the amplitude and $\omega_{n}$ being complex frequency. $\operatorname{Im}\left(\omega_{n}\right)$ represents the natural frequency of the system, and $\operatorname{Re}\left(\omega_{n}\right)$ is related to modal damping. Substituting q into Eq. (4.1) gives

$$
\left(\omega_{n}^{2} \mathbf{I}+\omega_{n} \mathbf{K}+\mathbf{C}\right) \overline{\mathbf{q}}=\mathbf{0}
$$

where $\mathbf{I}$ is a unit square matrix of the order $n$. Equation (4.2) constitutes a generalized eigenvalue problem and complex frequencies could be determined as a result. In the case of $\operatorname{Im}\left(\omega_{n}\right)=0$ the system loses stability by divergence, while the case of $\operatorname{Re}\left(\omega_{n}\right) \geqslant 0$ and $\operatorname{Im}\left(\omega_{n}\right) \neq 0$ corresponds to flutter. $\operatorname{Im}\left(\omega_{n}\right)$ varies along with the flow velocity $U_{i}$ and WOB $p$. It is called the critical flow rate $U_{c r}$ at which $\operatorname{Im}\left(\omega_{n}\right)$ decreases to zero from positive values. Similarly, the critical drill pressure $p_{c r}$, at which $\operatorname{Im}\left(\omega_{n}\right)$ dropped to zero from positive values, is also defined.

\subsection{Effect of Galerkin modal truncation}

For the problem at hand, the truncated number of Galerkin modal functions has a great influence on calculation accuracy. Païdoussis et al. (2008) pointed out that 40 or more eigenfunctions were necessary to achieve convergence for the drillstring-like system because of the very large gravity effect. Qi and $\mathrm{Hu}$ (2011) studied the effect of Galerkin modal truncation on natural frequencies of a cantilevered pipe conveying fluid. It was found that a low order mode contained information of higher order modes, and the truncated number $n$ exerted more influence on eigenvalues near the $n$-order. Since the amount of calculation increases exponentially along with growth of the truncated number, the determination of a reasonable $n$ is an important prerequisite. Here, taking $p=65 \mathrm{kN}$ as an example, we research relationships between the complex frequencies $\omega_{n}$ and internal flow $U_{i}$ downwards in the drillstring by solving Eq. (4.2) with different modal truncated numbers $n$, and present the results of the first four complex frequencies in Fig. 2. As $n$ increased, the curves for these four modes all converged. The results with $n=40$ and $n=50$ almost coincide completely. Therefore, $n=40$ is taken in this paper.

\subsection{Validation of the algorithm and model}

In order to validate correctness of the algorithm, the parameters from the literature (Zhang and Miska, 2005) are substituted into Eq. (4.2), and the first two eigenfrequencies are obtained, as shown in Fig. 3. For the first eigenfrequency, when the flow rate $U_{i}$ increases to $2.16 \mathrm{~m} / \mathrm{s}$, its imaginary part decreases to zero, and begins to bluckle. For the second eigenfrequency, when the flow rate increases to $19.89 \mathrm{~m} / \mathrm{s}$, its real part is equal to zero, and flutter instability occurs. 

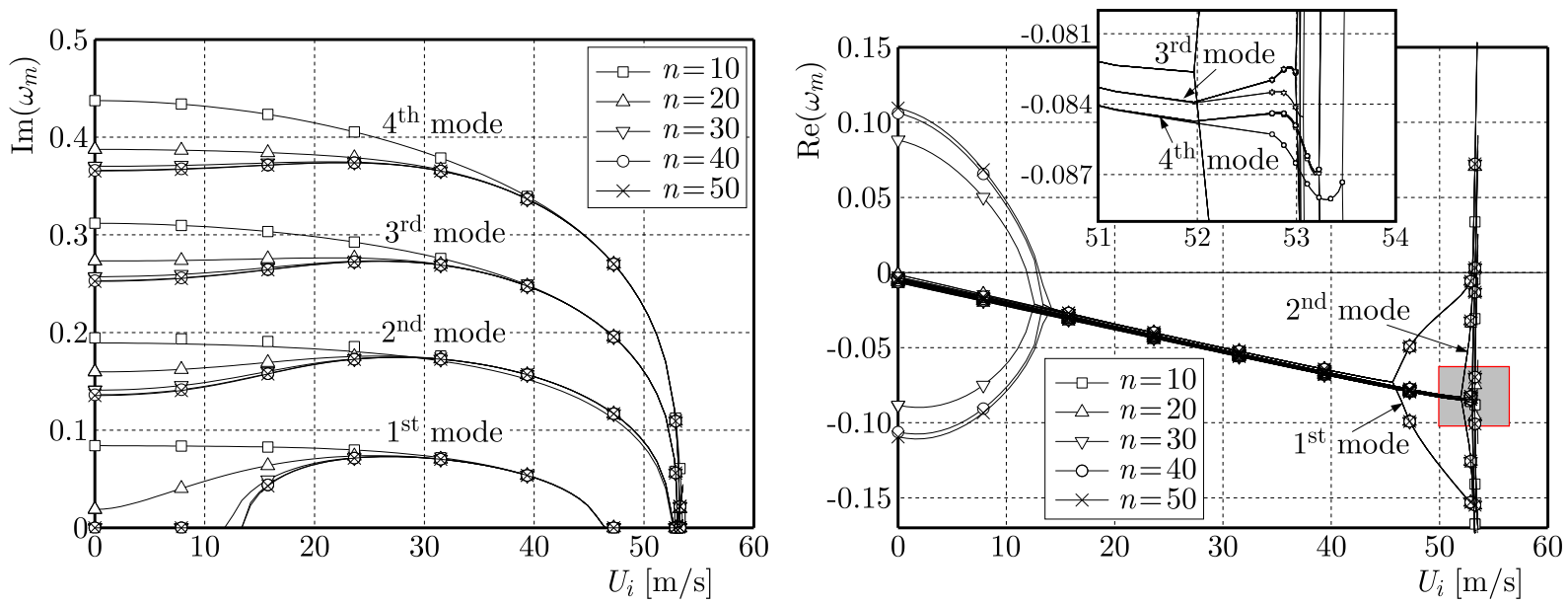

Fig. 2. Complex frequencies vs. flow velocities $U_{i}$ with different $n$ : (a) image parts of complex frequencies $\operatorname{Im}\left(\omega_{n}\right)$; (b) real parts of complex frequencies $\operatorname{Re}\left(\omega_{n}\right)$

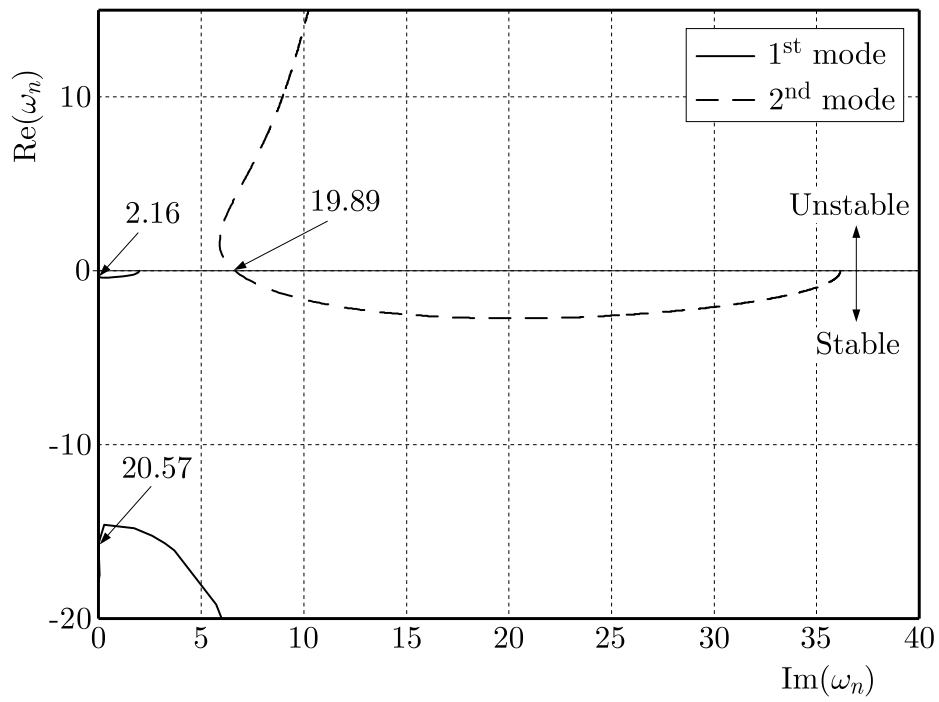

Fig. 3. The first two eigenfrequencies with the increasing flow rate $U_{i}$

So the critical flow rate of the first and second mode are $2.16 \mathrm{~m} / \mathrm{s}$ and $19.89 \mathrm{~m} / \mathrm{s}$. Compared with the results from literature (Zhang and Miska, 2005), the relative errors of the critical flow rate are $1.4 \%$ and $3.9 \%$, respectively. So the results are in good agreement with the literature (Zhang and Miska, 2005).

\subsection{Effect of parameters on stability}

The parameters, such as delivery capacity of the drilling fluid, WOB, drilling fluid density and wellbore diameter, are all important in drilling operation. Here, the effect of these parameters on stability of the drillstring system will be analyzed by solving eigenvalues of Eq. (4.2).

To begin with, the influence of the flow rate $U_{i}$ on system stability is presented by two examples. Firstly, the natural frequencies of the first 2 orders that are functions of $U_{i}$ are calculated under $p=40 \mathrm{kN}$, and the result is shown in Fig. 4a. It is found that $\operatorname{Im}\left(\omega_{n}\right)$ decreases monotonically as $U_{i}$ increases. When $U_{i}$ exceeds $42.9 \mathrm{~m} / \mathrm{s}$, the first natural frequency vanishes and the system loses its stability by divergence, namely, $U_{c r}=42.9 \mathrm{~m} / \mathrm{s}$. Secondly, the case of $p=65 \mathrm{kN}$ is taken as another example whose result, being very different from Fig. 4a, has been described in Fig. 2 (see lines corresponding to $n=40$ ). Under the condition of $U_{i}<17.3 \mathrm{~m} / \mathrm{s}$ or 
$U_{i}>34.4 \mathrm{~m} / \mathrm{s}$, the first natural frequency vanishes and the system is subject to divergence. In the range of $U_{i}=17.3-34.4 \mathrm{~m} / \mathrm{s}$, the first natural frequency increases firstly and then decreases along with increasing $U_{i}$, and the system is stable. Different trends between these two examples could be explained by reference to Eq. (2.3): the dimensionless flow rates $\left(u_{i}\right.$ and $\left.u_{o}\right)$ appear not only in the damping term, but also in the stiffness term. With an increase in the delivery rate, the contribution of the delivery rate to damping and stiffness changes, and stability of the system will change as a result. This phenomenon will be illustrated further in Fig. 5.

(a)

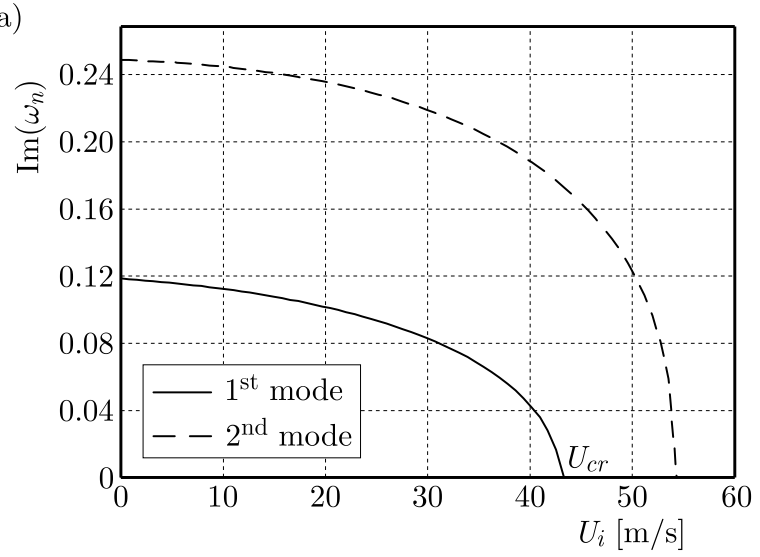

(b)

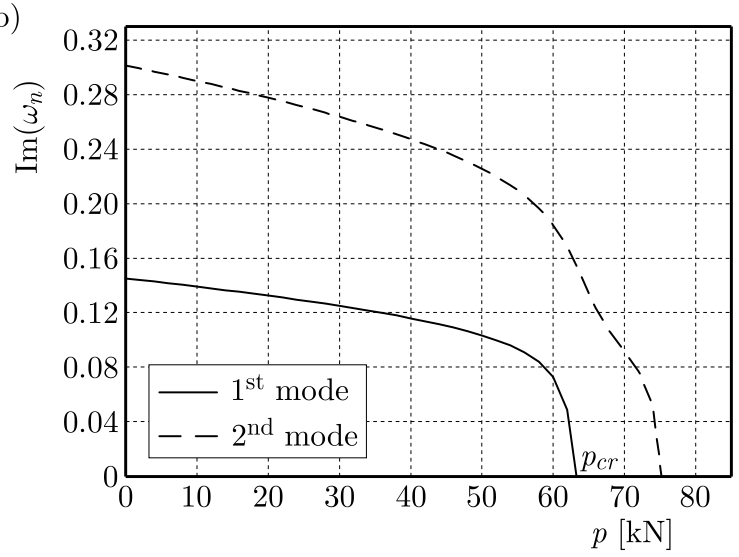

Fig. 4. The natural frequencies, $\operatorname{Im}\left(\omega_{n}\right)$, as a function: (a) of flow velocity $U_{i}$ for $p=40$, (b) of WOB $p$ for $U_{i}=5 \mathrm{~m} / \mathrm{s}$

(a)

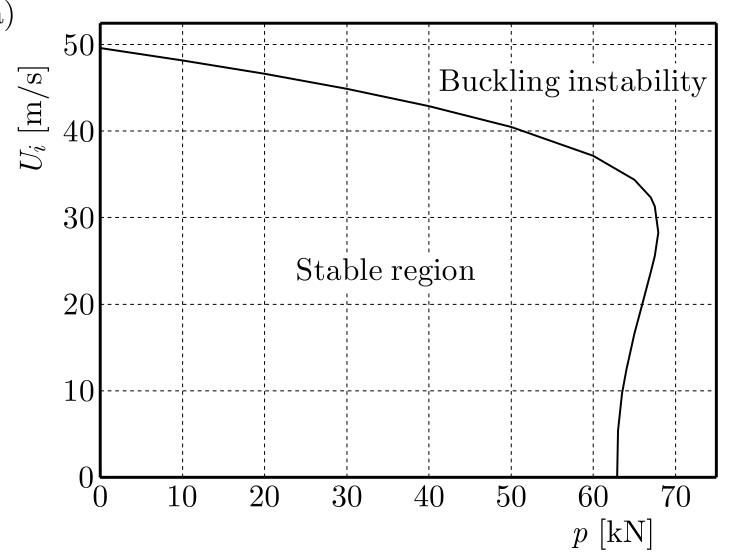

(b)

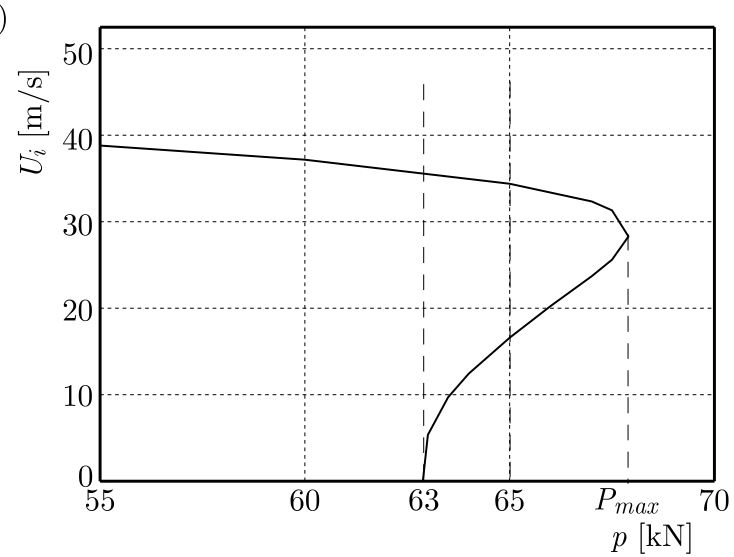

Fig. 5. Stable region in $\left(U_{i}-p\right)$ parameter plane; (b) is partial enlargement drawing of (a)

In addition, the influence of WOB $p$ on stability is given in Fig. $4 \mathrm{~b}$ which presents relationships between natural frequencies of the first 2 modes and $p$ for $U_{i}=5 \mathrm{~m} / \mathrm{s}$. With $p$ increasing, the natural frequencies diminish gradually and divergence instability eventually occurs. The critical WOB of instability $p_{c r}$ that corresponds to the first mode is $63.0 \mathrm{kN}$.

The effect of the flow rate and WOB on stability could also be shown in the parameter plane of $U_{i}$ and $p$ as Fig. 5, which indicates that the stable interval of $U_{i}$ diminishes as $p$ increases, namely, the higher the drilling pressure is, the more easily the system loses its stability. The effect of $U_{i}$ on stability varies for different $p$. Under the condition of $p<63.0 \mathrm{kN}$, the system varies from the stable region to an unstable region along with increasing $U_{i}$. When $p$ is between $63.0 \mathrm{kN}$ and $68.0 \mathrm{kN}$, the dynamic response of the drillstring system presents a process of "unstable-stable-unstable" as $U_{i}$ increases from zero (see Fig. 5b, the dash line of $p=65 \mathrm{kN}$ corresponds to Fig. 2). It indicates that the flow rate can promote stability under certain conditions. For $p>68.0 \mathrm{kN}$, the stability interval disappears and the system is in the unstable state for any velocities. The value of $68.0 \mathrm{kN}$ is called as "pressure limit of stability" and expressed as $P_{\max }$. 
Finally, the stiffness parameter of the stabilizer $k_{s t a b}$, the wellbore diameter $D_{w}$ and drilling fluid density $\rho$ also affect stability of the drillstring system.

The stiffness parameter of the stabilizer can be different for different operating conditions, and determination of the accuracy of the value is relatively difficult. When $k_{s t a b}$ is small, it can be used as a soft ground, and when it is large, it can be used as a hard formation. The stabilizer can be a fixed hinge if $k_{s t a b}$ is plenty large. The effect of different $k_{s t a b}$ on stability regions is shown in Fig. 6a. The stability regions gradually increase with the increasing $k_{\text {stab }}$, and when $k_{\text {stab }}=17.5 \cdot 10^{9} \mathrm{~N} / \mathrm{m}$ and $17.5 \cdot 10^{6} \mathrm{~N} / \mathrm{m}$, the stability regions are almost intact, which shows that the stabilizer is regarded as the fixed hinge in this case. In the case of $k_{s t a b}=17.5 \cdot 10^{6} \mathrm{~N} / \mathrm{m}$, the stability regions are only increased by about $10 \%$ compared with the case of $k_{\text {stab }}=0 \mathrm{~N} / \mathrm{m}$, and the trend of the critical flow rate as a fuction of $p$ is the same for different $k_{s t a b}$. So the stabilizer is ignored in the flowing analysis to save computer cost.

(a)

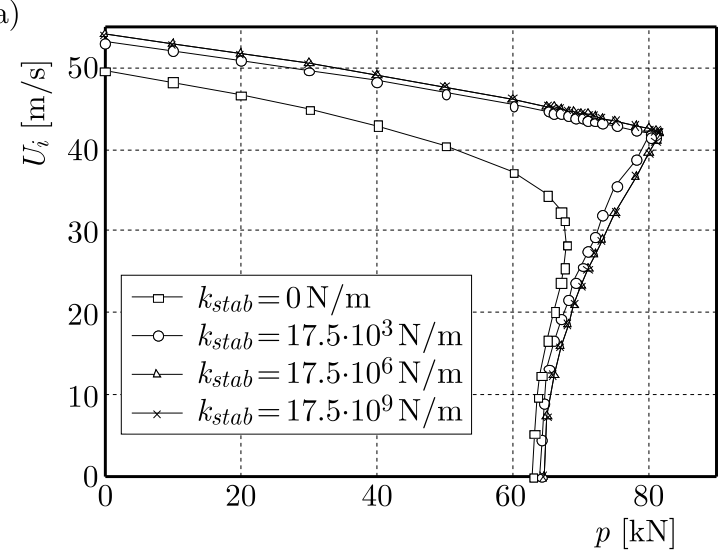

(b)

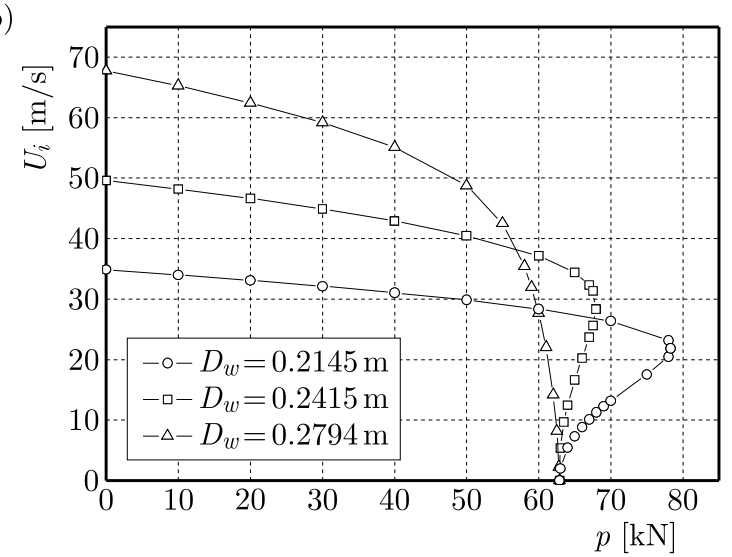

Fig. 6. Stable region in $\left(U_{i}-p\right)$ plane for different: (a) $k_{s t a b}$, (b) $D_{w}$

A larger $D_{w}$ that corresponds to a larger cross-sectional area of the annulus means lower velocity of the annular fluid. Figure $6 \mathrm{~b}$ shows stability regions in the $\left(U_{i}-p\right)$ plane for different $D_{w}$. For a smaller value of $D_{w}$, the stability region becomes narrower and $P_{\max }$ increases. when $D_{w}$ is $0.2794 \mathrm{~m}$, the critical velocity $U_{c r}$ decreases monotonically as $p$ is increasing, and $P_{\max }=63.0 \mathrm{kN}$ appears at the zero flow rate. In both cases of $D_{w}=0.2415 \mathrm{~m}$ and $0.2127 \mathrm{~m}, P_{\max }$ appears at a non-zero velocity, and the phenomenon of "unstable-stable-unstable" appears when $U_{i}$ increases from zero under the condition of $63 \mathrm{kN}<p<P_{\max }$. Figure 7 presents the effect of fluid density $\rho$ on stability regions in the $\left(U_{i}-p\right)$ plane. Larger $\rho$ leads to a lesser buoyant weight of the drillstring. With an increase of $\rho, U_{c r}$ decreases and $P_{\max }$ increases.

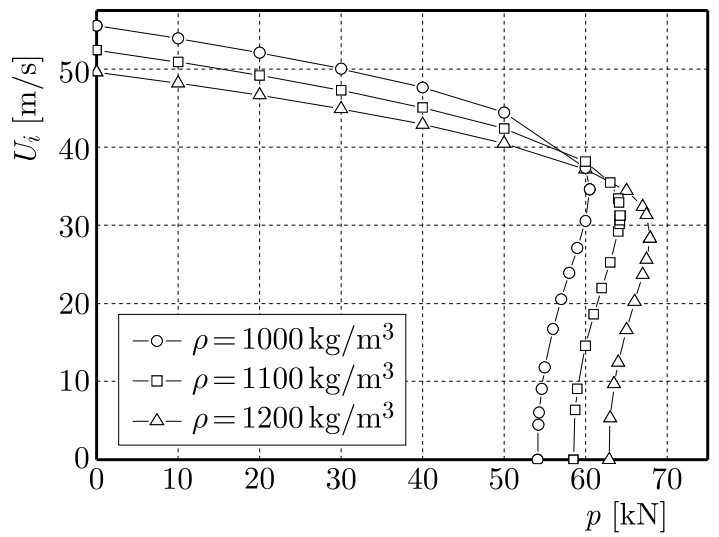

Fig. 7. Stable region in the $\left(U_{i}-p\right)$ plane for different $\rho$ 


\section{Stability analysis under fluctuating WOB}

The fluctuating WOB could be divided into two parts: the average pressure $p$ and harmonic pressure $p \mu \cos \bar{\omega} t$. Since the harmonic part exists, the dynamical system being nonautonomous with periodical internal variables, cannot be solved by the method of multiple scales for its significant gravitation effect. Here, Bolotin's method is adopted (Païdoussis and Issid, 1974).

\subsection{Bolotin's method}

Bolotin's method which is a kind of series method used to solve ordinary differential equations defines two types of parametric instabilities as the primary and secondary instability. For an undamped beam subjected to a harmonic end load, the primary instabilities occur at $2 \omega_{0 n} / \omega=1,3,5, \ldots$, where $\omega_{0 n}$ are the natural frequencies of the beam and $\omega$ is the dimensionless frequency of WOB. The secondary instabilities occur at $2 \omega_{0 n} / \omega=2,4,6, \ldots$ Of all these cases the most important is $2 \omega_{0 n} / \omega=1$ and 2 , the so-called principal primary instability and principal secondary instability, respectively. Solving Eq. (3.2) by Bolotin's method, one can obtain the primary and secondary instability of the drillstring system under fluctuating WOB.

To obtain the primary instabilities, the vector $\mathbf{q}$ of Eq. (3.2) is written as

$$
\mathbf{q}=\sum_{k=1,3,5, \ldots}\left[\mathbf{a}_{k} \sin \left(\frac{1}{2} k \omega \tau\right)+\mathbf{b}_{k} \cos \left(\frac{1}{2} k \omega \tau\right)\right]
$$

where $\mathbf{a}_{k}$ and $\mathbf{b}_{k}$ are all $n$-dimensional vectors. Substituting expression (5.1) into Eq. (3.2), one gets linear homogeneous equations for $\mathbf{a}_{k}$ and $\mathbf{b}_{k}$

$$
\begin{aligned}
& \left(-\frac{\omega^{2}}{4} \mathbf{I}+\mathbf{K}\right) \mathbf{a}_{1}-\frac{\omega}{2} \mathbf{C b}_{1}+\frac{1}{2} \mu \Gamma \mathbf{B a}_{3}-\frac{1}{2} \mu \Gamma \mathbf{B} \mathbf{a}_{1}=\mathbf{0} \\
& \left(-\frac{k^{2} \omega^{2}}{4} \mathbf{I}+\mathbf{K}\right) \mathbf{a}_{k}+\frac{1}{2} \mu \Gamma \mathbf{B}\left(\mathbf{a}_{k-2}+\mathbf{a}_{k+2}\right)-\frac{k \omega}{2} \mathbf{b}_{k}=\mathbf{0} \quad k=3,5,7, \ldots \\
& \frac{\omega}{2} \mathbf{C a}_{1}+\left(-\frac{\omega^{2}}{4} \mathbf{I}+\mathbf{K}\right) \mathbf{b}_{1}+\frac{1}{2} \mu \Gamma \mathbf{B b}_{3}+\frac{1}{2} \mu \Gamma \mathbf{B} \mathbf{b}_{1}=\mathbf{0} \\
& \frac{k \omega}{2} \mathbf{C a}_{k}+\left(-\frac{k^{2} \omega^{2}}{4} \mathbf{I}+\mathbf{K}\right) \mathbf{b}_{k}+\frac{1}{2} \mu \Gamma \mathbf{B}\left(\mathbf{b}_{k-2}+\mathbf{b}_{k+2}\right)=\mathbf{0} \quad k=3,5,7, \ldots
\end{aligned}
$$

To obtain the secondary instabilities, the $\mathbf{q}$ is expressed as

$$
\mathbf{q}=\sum_{k=2,4,6, \ldots}\left[\mathbf{a}_{k} \sin \left(\frac{1}{2} k \omega \tau\right)+\mathbf{b}_{k} \cos \left(\frac{1}{2} k \omega \tau\right)\right]
$$

Substituting Eq. (5.3) into Eq. (3.2) yields Eq. (5.4) similarly

$$
\begin{aligned}
& \left(-\omega^{2} \mathbf{I}+\mathbf{K}\right) \mathbf{a}_{2}+\frac{1}{2} \mu \Gamma \mathbf{B} \mathbf{a}_{4}-\omega \mathbf{C b}_{2}=\mathbf{0} \\
& \left(-\frac{k^{2} \omega^{2}}{4} \mathbf{I}+\mathbf{K}\right) \mathbf{a}_{k}+\frac{1}{2} \mu \Gamma \mathbf{B}\left(\mathbf{a}_{k-2}+\mathbf{a}_{k+2}\right)-\frac{k \omega}{2} \mathbf{C b}_{k}=\mathbf{0} \quad k=4,6,8, \ldots \\
& \mathbf{K b}_{0}+\frac{1}{2} \mu \Gamma \mathbf{B} \mathbf{b}_{2}=\mathbf{0} \\
& \omega \mathbf{C a}_{2}+\left(-\omega^{2} \mathbf{I}+\mathbf{K}\right) \mathbf{b}_{2}+\mu \Gamma \mathbf{B} \mathbf{b}_{0}+\frac{1}{2} \mu \Gamma \mathbf{B} \mathbf{b}_{4}=\mathbf{0} \\
& \frac{k \omega}{2} \mathbf{C a}_{k}+\left(-\frac{k^{2} \omega^{2}}{4} \mathbf{I}+\mathbf{K}\right) \mathbf{b}_{k}+\mu \Gamma \mathbf{B}\left(\mathbf{b}_{k-2}+\mathbf{b}_{k+2}\right)=\mathbf{0} \quad k=4,6,8, \ldots
\end{aligned}
$$

Only when the determinants of the coefficient matrices are equal to zero, which are presented as Eq. (5.5), do the linear homogeneous equations have non-zero solutions. Solving Eqs. (5.5) 
yields the critical frequencies that indicate the boundaries of the unstable regions. The coefficient matrices are of infinite orders, whose determinant is convergent, absolutely (Païdoussis and Issid, 1974). One could obtain the critical frequencies with adequate precision by setting $k=1$ for the primary region and $k=2$ for the secondary one

$$
\begin{array}{cccccc}
\cdots & \multicolumn{1}{c}{\cdots} & \cdots & \cdots \\
\cdots & -\frac{\omega^{2}}{4} \mathbf{I}+\mathbf{K}-\frac{1}{2} \mu \Gamma \mathbf{B} & -\frac{\omega}{2} \mathbf{C} & \cdots \\
\cdots & & \frac{\omega}{2} \mathbf{C} & -\frac{\omega^{2}}{4} \mathbf{I}+\mathbf{K}+\frac{1}{2} \mu \Gamma \mathbf{B} & \cdots \\
\cdots & & \cdots & & \cdots & \cdots
\end{array} \mid=0
$$

The truncated number $n$ of Galerkin modal functions also affects results of Eqs. (5.5). Denoting $\omega_{01}$ as the first natural frequency at the zero flow and zero drilling pressure, Table 1 shows the calculated relative critical frequencies $\omega / \omega_{01}$ corresponding to different $n$ for $k=1$ and $k=2$, respectively. It is found that $\omega / \omega_{01}$ converges gradually as $n$ increases. For $k=1$, the results with $n=30$ and $n=35$ have no difference, so $n$ is taken as 30. Similarly, $n$ is taken as 20 for $k=2$. These two truncated numbers will be used in the following analysis.

Table 1. The calculated results of $\omega / \omega_{01}$ with different $n$

\begin{tabular}{|c|c|c|c|c|c|}
\hline \multirow{2}{*}{$k=1$} & \multicolumn{5}{|c|}{$n$} \\
\cline { 2 - 6 } & 10 & 20 & 25 & 30 & 35 \\
\hline \hline$\omega / \omega_{01}$ & 1.9425 & 1.9406 & 1.9405 & 1.9404 & 1.9404 \\
\hline \multirow{2}{*}{$k=2$} & \multicolumn{5}{|c|}{$n$} \\
\cline { 2 - 6 } & 10 & 20 & 25 & 30 & 35 \\
\hline \hline$\omega / \omega_{01}$ & 0.9770 & 0.9713 & 0.9705 & 0.9703 & 0.9703 \\
\hline
\end{tabular}

\subsection{Stability analysis}

The dynamic stability of the system will be analyzed under the condition of $p=40 \mathrm{kN}$ and $U_{i}=5 \mathrm{~m} / \mathrm{s}$, and other parameters are the same as in Section 4 . The boundaries of primary and secondary instability regions associated with the first four modes could be obtained by solving Eqs. (5.5) as the amplitude parameter $\mu$ of WOB varies between 0 and 1 (see Fig. 8). When $\mu$ increases to $0.06,0.12,0.16$ and 0.24 from zero, the primary instability regions of the first four modes appear, in turn, at $\omega / \omega_{01}=1.7,3.5,5.3$ and 7 , respectively. The interval of $\omega / \omega_{01}$ corresponding to the instability region increases along with increasing $\mu$. Therefore, the greater the fluctuating amplitude of WOB is, the easier the system is apt to be unstable. Compared with the primary instability regions, the regions of secondary instability are much smaller, and the majority of them are located within the primary instability areas of the first and second modes. As a result, the effect of $p, U_{i}, \rho$ and $D_{w}$ on the stability will be described only by the first two modes of the primary instability.

\subsection{Effect of parameters on stability}

The primary instability regions of the first two modes are presented in the $\left(\omega / \omega_{01}-\mu\right)$ plane. Figure 9a shows the effect of the average WOB $p$ on the instability of the drillstring system. 


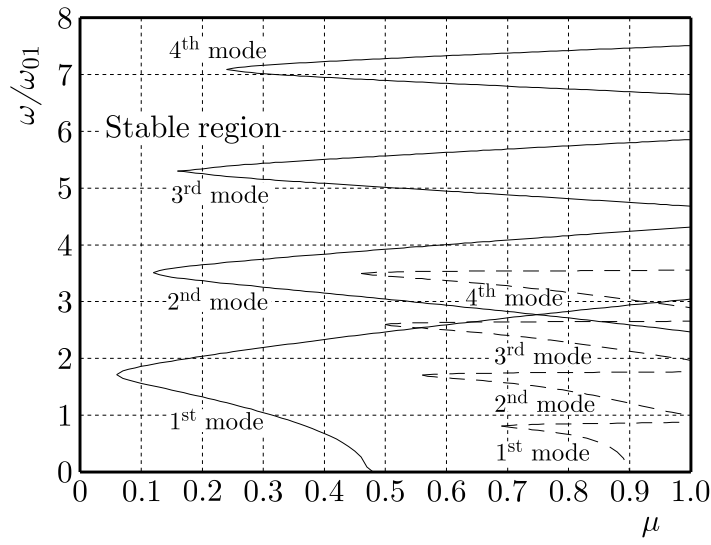

Fig. 8. Parametric instability boundaries; the solid lines are principal primary instability boundaries while the dash lines are principal secondary instability boundaries

(a)

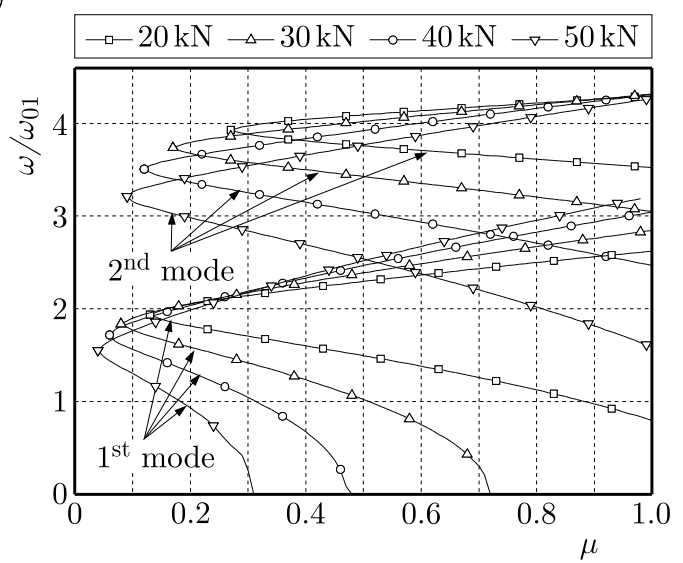

(b)

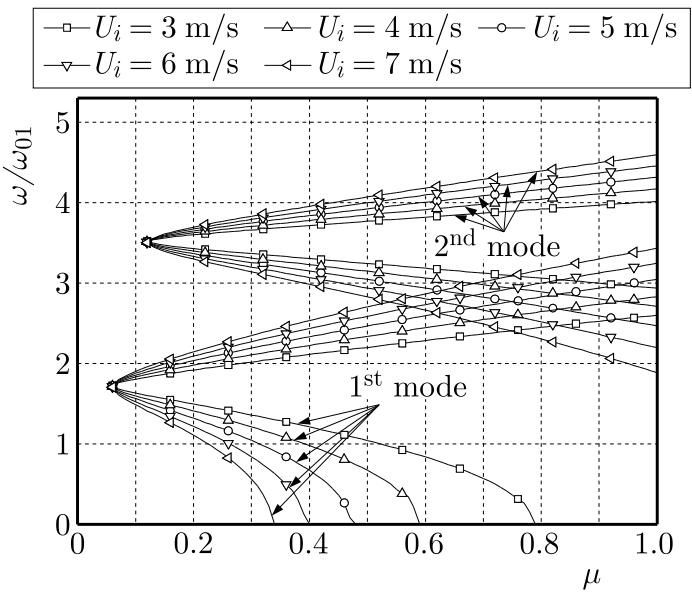

Fig. 9. The primary instability boundaries of the first two modes: (a) for four values of $p$, (b) for five values of $U_{i}$

(a)

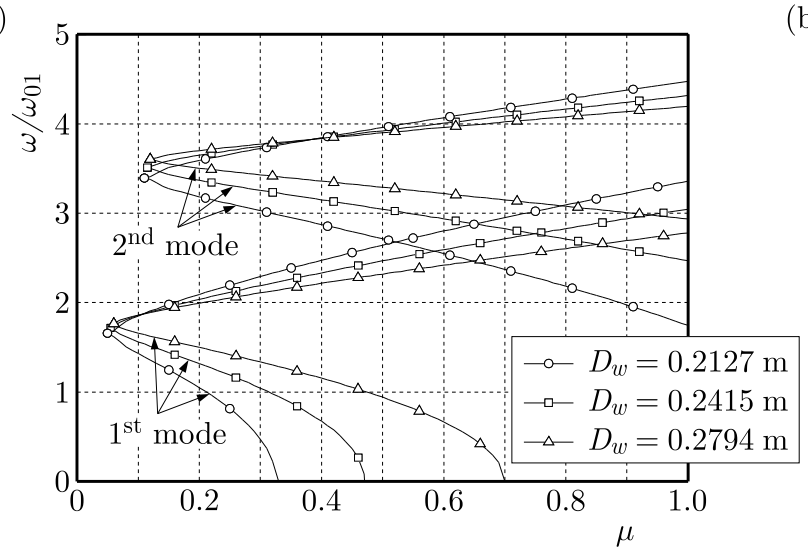

(b)

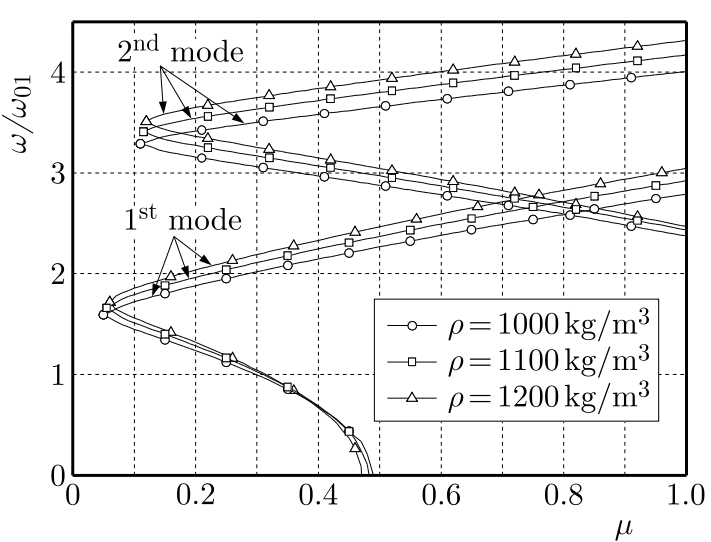

Fig. 10. Primary instability boundaries of the first two modes: (a) for three values of $D_{w}$, (b) for three values of $\rho$

As $p$ increases, the instability regions move downwards and left, which means a decrease of the critical frequencies $\omega / \omega_{01}$ and $\mu$ along with the increasing $p$. It is also noted that the regions of instability are larger for higher $p$. Therefore, the system with higher $p$ is more apt to be unstability. 
The instability boundaries for five values of the flow rate $U_{i}$ are illustrated in Fig. 9b, where the left most points of the curves for each mode almost coincide, and instability regions are more extensive at higher flow rates. It is evident that larger $U_{i}$ leads to poor dynamic stability.

Increasing the borehole diameter $D_{w}$ will reduce the velocity of the annular fluid. The impact of $D_{w}$ on parametric instability of the system is shown in Fig. 10a. As $D_{w}$ increases, the instability regions become smaller. It means that the higher is the annulus flow velocity, the worse stability is. This result is somewhat similar to Fig. 9b. In other words, delivery capacity destabilizes the drillstring system loaded by the harmonic WOB.

Figure 10b shows the effect of fluid density $\rho$, which influences the buoyant weight of the drillstring and hydrodynamic forces on the stability of the system. It is noted that the instability regions move upwards as $\rho$ increases. It reflects that the critical frequency increases with larger $\rho$, but not very seriously.

\section{Conclusion}

The dynamic stability of the drillstring system that is modeled by a simply supported pipe conveying drilling mud inside and outside the drillstring, both with constant WOB and fluctuating WOB, is explored, and the following conclusions have been drawn.

1) For the drilling process under constant WOB, the WOB is the driving force of destabilization of the system, whereas the flow rate, which affects stiffness and damping of the system simultaneously, plays a complex role. Generally, the system is subject to divergence at higher flow rates, but under a certain combination of parameters, the internal fluid velocity $U_{i}$ stabilizes the drillstring. In addition, the ranges of stable regions become broader with increasing the annulus area, and the stable regions move towards lower $U_{i}$ and higher $p$ as the fluid density increases.

2) Under the fluctuating WOB, the drilling parameters, including the average value and fluctuating amplitude of the WOB and the delivery capacity of drilling fluid, are all driving forces of instability. As the fluid density increases, stability of the drillstring system decreases, but this effect is small.

\section{Acknowledgments}

This project was supported by the National Natural Science Foundation of China (51134004) and the National Key Research and Development Program of China, Grant No. 2016YFC0802100.

\section{References}

1. Abdelbaki A.R., Pä̈Doussis M.P., Misra A.K., 2019, A nonlinear model for a hanging tubular cantilever simultaneously subjected to internal and confined external axial flows, Journal of Sound and Vibration, 449, 349-367

2. Abdelbaki A.R., Païdoussis M.P., Misra A.K., 2020, A nonlinear model for a hanging cantilevered pipe discharging fluid with a partially-confined external flow, International Journal of Non-Linear Mechanics, 118, 103290

3. Asghar Jafari A., Kazemi R., Faraji Mahyari M., 2012, The effects of drilling mud and weight bit on stability and vibration of a drillstring, Journal of Vibration and AcousticsTransactions of the Asme, 134, 1, 1-9

4. Dunayevsky V.A., Fereldoun A., Arnis J., 1993, Dynamic stability of drillstrings under fluctuating weight on bit, SPE Drilling and Completion, 8, 2, 84-92

5. Ghasemloonia A., Rideout D.G., Butt S.D., 2013, Coupled transverse vibration modeling of drillstrings subjected to torque and spatially varying axial load, Proceedings of the Institution of Mechanical Engineers. Part C: Journal of Mechanical Engineering, 227, C5, 946-960 
6. Ghasemloonia A., Rideout D.G., Butt S.D., 2014, Analysis of multi-mode nonlinear coupled axial-transverse drillstring vibration in vibration assisted rotary drilling, Journal of Petroleum Science and Engineering, 116, 36-69

7. Hannoyer M.J., PAÏDoussis M.P., 1978, Instabilities of tubular beams simultaneously subjected to internal and external axial flows, ASME Journal of Mechanical Design, 100, 328-338

8. Łuczko J., Czerwiński A., 2015, Parametric vibrations of flexible hoses excited by a pulsating fluid flow, Part I: Modelling, solution method and simulation, Journal of Fluids and Structures, 55, 155-173

9. Mohammadzadeh M., Shahgholi M., Arbabtafti M., Yang J.M., 2020, Vibration analysis of the fully coupled nonlinear finite element model of composite drill strings, Archive of Applied Mechanics, 90, 6, 1373-1398

10. Ni Q., WANG Y., TANG M., LuO Y., YAN H., WANG L., 2015, Nonlinear impacting oscillations of a fluid-conveying pipe subjected to distributed motion constraints, Nonlinear Dynamics, 81, 893-906

11. PAÏDoussis M.P., Issid N.T., 1974, Dynamic stability of pipes conveying fluid, Journal of Sound and Vibration, 33, 267-294

12. Païdoussis M.P., Luu T.P., Prabhakar S., 2008, Dynamics of a long tubular cantilever conveying fluid downwards, which then flows upwards around the cantilever as a confined annular flow, Journal of Fluids and Structures, 24, 111-128

13. PAnda L.N., KAR R.C., 2008, Nonlinear dynamics of a pipe conveying pulsating fluid with combination, principal parametric and internal resonances, Journal of Sound and Vibration, 309, 375-406

14. Pei Y.C., Sun Y.H., WAng J.X., 2013, Dynamics of rotating conveying mud drillstring subjected to torque and longitudinal thrust, Meccanica, 48, 2189-2201

15. QI H.H., XU J., 2011, Effect of Galerkin modal truncation on natural frequency analysis of a cantilevered pipe conveying fluid, Journal of Vibration and Shock, 30, 148-151

16. QIAN Q., WANG L., Ni Q., 2008, Vibration and stability of vertical upward-fluid-conveying pipe immersed in rigid cylindrical channel, Acta Mechanica Solida Sinica, 21, 431-440

17. REN F.S., YAo Z.G., 2013, Study on nonlinear dynamics and bifurcations in rotating compressivedrillstring, Engineering Mechanics, 30, 1, 251-256

18. Tang S., Liang Z., Zhao G.H., 2018, Dynamic stability of lateral vibration of a tubing string in flowing production, Journal of Vibroengineering, 20, 7, 2540-2549

19. Umbetkulova A., Khajiyeva L., 2017, Analysis of drill string nonlinear vibrations with its own weight, News of the National Academy of Sciences of the Republic of Kazakhstan, Series of Geology and Technical Sciences, 42, 1, 217-225

20. WANG L., 2009, A further study on the nonlinear dynamics of simply supported pipes conveying pulsating fluid, International Journal of Non-Linear Mechanics, 44, 115-121

21. WANG L., 2012, Flutter instability of supported pipes conveying fluid subjected to distributed follower forces, Acta Mechanica Solida Sinica, 25, 1, 46-52

22. Wang L., Kuang Y., Huang Y., Ni Q., 2010, Recent development on vibration and stability of pipes conveying fluid from macro-scale to nano-scales, Acta Mechanica Solida Sinica, 31, 5, 481-495

23. Wen X., Guan Z.C., Liang D.Y., Zhou Y.C., 2019, Proportion tests for transverse vibration laws of rotary drill string in a highly deviated well, Journal of Vibration and Shock, 38, 9, 216-222

24. Xu J., Wang L., 2015, Dynamics and Control of Fluid-Conveying Pipe Systems, Science Press, Beijing

25. Zhang Q., Miska S., 2005, Effects of flow-pipe interaction on drill pipe buckling and dynamics, Journal of Pressure Vessel Technology, 127, 129-136 